\title{
Lições da Universidade Popular dos Movimentos Sociais na África Austral: terra, luta e emancipação
}

\author{
Lessons from the Popular University of Social Movements in Southern Africa: land, struggle and \\ emancipation
}

\author{
Lecciones de la Universidad Popular de los Movimientos Sociales en África Austral: tierra, lucha y \\ emancipación
}

\author{
BOAVENTURA MONJANE ${ }^{1}$ \\ SAm Moyo African InStitute of Agrarian STUdies, SMAIAS, Harare, Zimbábue \\ Universidade de Coimbra, UC, Coimbra, Portugal
}

\begin{abstract}
RESUMO
Este ensaio debruça-se em volta das experiências e das lições aprendidas no e com o processo da organização e realização de oficinas da Universidade Popular de Movimentos Sociais, UPMS, em Moçambique e Zimbábue em 2013, 2014 e 2016 respetivamente. O artigo divide-se em três partes principais. Na primeira, traz-se uma breve discussão em volta da crise da educação convencional, principalmente a partir das teorizações de Paulo Freire e de Boaventura de Sousa Santos e faz-se alusão à questão da crise dos sistemas de educação em África. Na segunda parte, apresenta-se a UPMS e se revê os trabalhos produzidos sobre esta proposta até aqui. A terceira parte traz as experiências das três oficinas realizadas em Mumemo, Tete e Harare, discutindo, nas conclusões, em volta das lições que se podem aprender deste processo para o caso de Moçambique e Zimbábue.
\end{abstract}

Palavras-chave: Educação Popular. UPMS. Movimentos Sociais. Moçambique. Zimbábue.

\begin{abstract}
This essay focuses on the experiences and lessons learned in and with the process of organizing and helding workshops of the Popular University of Social Movements, UPMS, in Mozambique and Zimbábue in 2013, 2014 and 2016 respectively. The article is divided into three main parts. In the first one, there is a brief discussion about the crisis of conventional education, mainly from the theorizations of Paulo Freire and Boaventura de Sousa Santos, as well as an allusion to the crisis of education systems in Africa. In the second part, it presents the UPMS and briefly reviews the work produced under this proposal so far. The third part presents the experiences of the three workshops held in Mumemo, Tete and Harare, discussing in the conclusions about the lessons that can be learned from this process in the case of Mozambique and Zimbabwe.
\end{abstract}

Keywords: Popular Education. UPMS. Social Movements. Mozambique. Zimbabwe.

\section{RESUMEN}

Este ensayo se centra en las experiencias y las lecciones aprendidas en el proceso de organización y realización de talleres de la Universidad Popular de Movimientos Sociales, UPMS, en Mozambique y Zimbabue en 2013, 2014 y 2016 respectivamente. El artículo se divide en tres partes principales. En la primera, se trae una breve discusión en torno a la crisis de la educación convencional, principalmente a partir de las teorizaciones de Paulo Freire y de Boaventura de Sousa Santos y se alude a la cuestión de la crisis de los sistemas de educación en África. En la segunda parte, se presenta la UPMS y se revisa los trabajos producidos sobre esta propuesta hasta aquí. La tercera parte trae las experiencias de los tres talleres realizados en Mumemo, Tete y Harare, discutiendo, en las conclusiones, alrededor de las lecciones que se pueden aprender de este proceso para el caso de Mozambique y Zimbabue.

Palabras clave: Educación Popular. UPMS. Movimientos Sociales. Mozambique. Zimbabue.

\footnotetext{
${ }^{1}$ Pesquisador do SMAIAS e doutorando do Centro de Estudos Sociais/Faculdade de Economia da UC. Bolsista da Fundação para a Ciência e a Tecnologia (FCT). E-mail: boa.monjane@gmail.com
} 


\section{INTRODUÇÃOO}

É cada vez mais consensual que a educação convencional (escolar), em todos os níveis, experimenta uma crise profunda. Em todos os quadrantes do mundo a escola e a universidade, para além de serem, em vários casos, reprodutoras do status quo, não têm podido cumprir com o (seu) papel de produzir e fornecer à sociedade conhecimento útil para a sua reinvenção. Já dizia Lenin ${ }^{2}$ que "[...] a escola, à margem da vida e à margem da política, é falsidade e hipocrisia" (LENIN, 1978, p. 398).

Nos últimos dez anos, Boaventura de Sousa Santos tem vindo a teorizar profundamente sobre a crise da universidade - e, por extensão, sobre a crise da educação convencional - ao expor a incapacidade destes lugares convencionais de valorizarem outros tipos de saberes, não oriundos da ciência hegemônica, eurocêntrica, mas úteis para a emancipação e transformação sociais.

Sobre esta temática, Santos (2007) coloca no centro das suas análises, e em "confronto" com a universidade convencional, os movimentos sociais, como classes populares excluídas, mas detentoras de saberes produzidos no processo das suas lutas por justiça e transformação (social, política, econômica etc.). De fato, e segundo defende Gadotti (2009), os movimentos sociais ensinam-nos que o povo, as pessoas, se educam na luta. A luta é, por conseguinte, pedagógica e contém um "saber de experiência feito" (FREIRE, 1997).

Em 2003, durante o Fórum Social Mundial, foi proposta a criação da Universidade Popular dos Movimentos Sociais (UPMS), com o objetivo de "[...] proporcionar a auto-educação dos activistas e dirigentes dos movimentos sociais, bem como dos cientistas sociais, dos investigadores e artistas empenhados na transformação social progressista" (SANTOS, 2006, p. 168).

Dez anos depois da realização de várias oficinas da UPMS na América Latina e na Europa, realizou-se, em março de 2013, a primeira oficina da UPMS em África, na cidade de Túnis, Tunísia, no âmbito da realização do Fórum Social Mundial. O evento inspirou os participantes de Moçambique a proporem a realização de uma oficina no seu país, o que veio a concretizar-se em julho de 2013, em Mumemo, Maputo. A oficina de Mumemo inspirou a realização, em novembro de 2014, de outra, na cidade de Tete, centro de Moçambique. Estas oficinas ficaram registadas como as primeiras na África Subsaariana.

A partir de um encontro entre Boaventura de Sousa Santos ${ }^{3}$ e Elizabeth Mpofu ${ }^{4}$, num evento organizado pelos parceiros da UPMS, em março de 2015, no âmbito da edição do Fórum Social Mundial, surgiu a proposta de se realizar uma oficina da UPMS em Harare, Zimbábue, o que veio a acontecer em julho de 2016.

Para além de Tunísia, Moçambique e Zimbábue, realizou-se, em julho de 2015, uma oficina da UPMS em Cabo Verde e outra mais recentemente nos acampamentos de refugiados na Sahara Ocidental.

\section{A CRISE DA EDUCAÇÃo ESCOLAR}

A máxima a seguir de Rui Canário é deveras citada em trabalhos que discutem, atualmente, o papel da escola na sociedade: "A escola deixou de estar em harmonia com o mundo social, pela razão simples de que o mundo para que foi criada não existe"

\footnotetext{
${ }^{2}$ Discurso no I Congresso de Instrução Pública, realizado em 28 de agosto de 1918.

${ }^{3}$ Proponente da UPMS e Diretor do Centro de Estudos Sociais (CES) da Universidade de Coimbra.

${ }^{4}$ Presidente do Fórum dos Pequenos Produtores Orgânicos do Zimbábue (ZIMSOFF) e coordenadora geral da Via Campesina Internacional.
} 
(CANÁRIO, 2002, p. 9). Este autor realizou importantes reflexões sobre as limitações do ensino convencional: denunciou a subordinação da escola à hegemonia da racionalidade econômica e defendeu a existência de desarmonia entre a escola e o mundo. Para Canário (2002), “[...] a educação tornou-se refém do escolar o que se torna problemático numa época em que assistimos, por parte da escola, a uma perda de coerência quer interna [...] quer externa" (p. 9).

O fato não está, contudo, tanto num mundo que não existe, mas sim numa visão do mundo que condiciona e faz da escola um instrumento a seu serviço, ignorando outras visões de outros mundos existentes e possíveis. O ponto conflituoso nas políticas de educação convencional tem a ver com o fato de que os programas e as propostas metodológicas que se empregam não são coerentes com a diversidade do mundo. Os currículos educativos tendem a ser homogêneos, reproduzindo a monocultura do saber científico eurocêntrico em sociedades tão plurais (SANTOS, 2007).

Estudiosos trouxeram valiosas contribuições na análise das limitações, contradições e crise da educação escolar, criticando o seu caráter bancário ${ }^{5}$ e sugerindo sua humanização, reinvenção e transformação. Embora tenha sido no contexto norteamericano, o trabalho de Hannah Arendt (1961) foi determinante para a análise do fenômeno (principalmente no ensino de crianças e adolescentes) em outros lugares do mundo. O trabalho do educador brasileiro Paulo Freire (FREIRE, 1967; 1987; 1997; 2001; 2002) foi fortemente determinante ao alertar a necessidade de descolonizar a educação, desafiar sua ideologia neoliberal, reconsiderar e reconstruir a relação e o papel social entre os que ensinam e os que aprendem. Inspirados por Freire, Gadotti (2012) e Maciel (2011) trouxeram debates valiosos em volta da educação popular, ressaltando a sua característica emancipatória e alertando para a necessidade da sua priorização, principalmente no contexto brasileiro.

De acordo com Maciel (2011),

A Educação Popular, na ótica de Freire, se faz popular pelo potencial de organização da classe trabalhadora, possui em sua essência a contestação do sistema político e da ordem econômica vigente. Sua teoria é incorporada por grupos de educadores, militantes e trabalhadores dos movimentos populares para embasar suas práticas educativas (p. 338).

Em África, um dos desafios mais importantes no período imediatamente após as independências foi a construção de sistemas de educação que fossem inclusivos, populares e que respondessem às necessidades dos novos contextos das nações novas. Samora Machel, o primeiro presidente da então República Popular de Moçambique (1975 a 1986), acreditava que a função da escola - ou seja, da educação - era de permitir às populações a aquisição de ferramentas para uma melhor participação de cidadania. Uma das frases mais ressonantes de Machel sobre o papel da escola foi: "[...] fazer da escola a base para o povo tomar o poder" (MACHEL, 1974). Tomar o poder, nas palavras daquele líder, significava fazer com que o povo se emancipasse para que, depois de séculos de opressão colonial, os subalternos pudessem transformar o seu meio e construir, eles próprios, a nação pela qual lutaram para libertar.

A solidariedade internacional, principalmente entre os Países não Alinhados ${ }^{6}$, permitiu que houvesse intercâmbios entre os países recém-independentes e aqueles que tinham alcançado as suas independências, como foi o caso do Brasil e Chile.

\footnotetext{
5 "Educação bancária" (FREIRE, 1987).

6 "[...] países que defendiam a postura de não integrar o bloco capitalista ou socialista, mantendo-se distantes das projeções de poder das grandes potências" (CADORE; THEODORO; OLIVEIRA, 2017, p. 13).
}

Motricidades: Rev. SPQMH, v. 2, n. 2, p. 163-174, maio-ago. 2018 | ISSN 2594-6463 |

DOI: http://dx.doi.org/10.29181/2594-6463.2018.v2.n2.p163-174 
Na década de 1970, e no âmbito desse espírito de intercâmbio e solidariedade, Paulo Freire contribuiu na construção de sistemas de educação em países que tinham conquistado sua independência ou estavam e via de fazê-lo em África. Sua primeira visita ao continente foi nos finais de 1971, quando se deslocou para a Zâmbia e Tanzânia. Segundo Gadotti (2012):

\begin{abstract}
A experiência de Paulo Freire na zona rural e nas periferias urbanas destes países, serviu de fonte de inspiração para um novo desenvolvimento de sua teoria emancipadora da educação, entendida como ato político, ato produtivo e ato de conhecimento. Com base em sua nova experiência em campanhas de alfabetização, ele sublinhou a importância da associação entre o processo de alfabetização e o processo produtivo [...], bem como o papel da "pósalfabetização" como forma de dar continuidade ao processo de alfabetização (p. 56-57).
\end{abstract}

Em vários lugares em África pós-colonial, os sistemas educativos tiveram um caráter revolucionário, inclusivo e criativo, como foram os casos de Moçambique e Guiné Bissau. Com a entrada do neoliberalismo nos países africanos, contudo, essa trajetória foi ficando progressivamente interrompida. As novas lógicas da educação foram acompanhando o processo da globalização hegemônica e o seu propósito transformador foi ficando aos poucos comprometido. Com a intensificação do neoliberalismo, principalmente a partir da década de 1990, a degeneração da educação nos países africanos foi tal que os níveis de insatisfação, tanto de estudantes como de professores, agudizou-se. O recorrente levante de estudantes, professores e pessoal administrativo de centros de ensino, particularmente das universidades, em vários países, é prova disso.

A atual crise do sistema educacional na África do Sul, cuja manifestação culminou com fortes protestos de estudantes universitários ${ }^{7}$ por uma educação nacional gratuita - a campanha fees must fall (as taxas devem cair), obrigou as autoridades a encerrarem várias universidades naquele país. $\mathrm{O}$ fato é que os protestos de estudantes representam a ponta do iceberg de um problema maior em todo o sistema educacional na África do Sul. Em janeiro de 2016, ao reagir ao fracasso de estudantes dos níveis iniciais, o governo sul-africano reconheceu que "[...] isto é semelhante a uma crise nacional" (NKOSI, 2016).

Em países como a Etiópia, a Nigéria e a Zâmbia, mais da metade dos alunos matriculados não aprendem as habilidades básicas até ao fim do nível primário (FLEET, 2012).

Num artigo intitulado "A falha da educação na África Subsaariana”, Khwaja (2014) afirma que o sistema educacional em África não pode e não irá produzir gente letrada, criativa e funcionários ou empreendedores que resolvam problemas o necessário para o sucesso na economia global. Ou seja, na ótica desta articulista, e, na verdade, na narrativa neoliberal dominante, a educação é um meio de treinamento de capital humano capaz de produzir e prestar serviços.

Por outro lado, a literatura sobre o fracasso do sistema de educação em África utiliza ferramentas de medição na base daquilo que seria adequado na lógica capitalista. Em África, os sistemas de educação são a mais hegemônica forma através da qual a colonialidade persiste.

Umas das questões mais discutidas no que concerne aos sistemas de educação em África é, contudo, a marginalidade econômica relativa à pobreza e subordinação das

\footnotetext{
${ }^{7}$ Os protestos dos estudantes são severamente reprimidos pelas forças policiais sul-africanas.
} 
mulheres, principalmente no meio rural. As conclusões dessas discussões apontam para o fato da maioria das mulheres em África ter ainda pouco acesso à educação em relação aos homens. Pesquisas sobre questões de gênero em África mostram que as estruturas educacionais tendem a perpetuar a ordem existente em vez de centrar-se na questão da disparidade de gênero (AGYEPONG, 2001).

Seria, contudo, impróprio auferir que, toda a lógica da educação escolar e convencional é por si incorreta em África. Ela é, aí está, resultado de imposições indiscriminadas feitas por organismos multilaterais, que impõem currículos, metodologias e metas numéricas a alcançar, sem levar em conta a participação protagonista dos educandos como sujeitos determinantes no processo de transformação social. É uma educação que, não só não promove, como nega a inserção crítica (FREIRE, 1987). Na sua maioria, os sistemas de ensino em África não são genuinamente desenhados localmente na base das condições e da realidade concreta e objetiva dos educandos.

\section{A Universidade Popular dos Movimentos Sociais: uma proposta de AUTOAPRENDIZAGEM COLETIVA E TRANSFORMADORA}

Embora atuando num campo fora das estruturas e da lógica da educação convencional (por não fornecer formação profissional e de carreira e nem sequer estar dirigida com a mesma lógica eurocêntrica de formação para graduação), a UPMS traz uma valiosa contribuição ao dirigir sua abordagem aos movimentos sociais em articulação com intelectuais das universidades e centros de pesquisa comprometidos com as lutas populares.

Há, certamente, em todas as regiões do mundo, várias iniciativas criativas e emancipatórias desafiando a lógica da educação bancária. Em África Austral ${ }^{8}$, as experiências de formação política promovidas por movimentos sociais, como é o caso do Diálogo dos Povos, La Via Campesina e a Assembleia das Mulheres Rurais (para citar casos em que estive diretamente envolvido), têm provado eficiência na capacidade de introduzir uma perspectiva de troca de conhecimento entre seus pares, geralmente lideranças dos movimentos e ativistas de vários setores de lutas sociais - camponeses, mulheres rurais, pescadores de pequena escala, ecologistas, trabalhadores.

Tal como reconhece Boaventura de Sousa Santos, há sobretudo na América Latina e em África uma rica tradição de educação popular, contudo, essa educação popular continua muito assente na distinção entre educador e educando:

E portanto, é uma transmissão de conhecimentos que [...] em geral podemos
dizer que ainda vigora um pouco [...] há uma certa ideia de transmissão de
conhecimento, em que os educandos estão, fundamentalmente, como
recipientes onde se depositam novos conhecimentos ainda que por uma via
politicamente motivada, politicamente ativa, para a mobilização social, fora
das instituições formais de educação, por isso é que eu chamo de popular que
é porque não tem lugar dentro das instituições formais de educação
(SANTOS, 2011, p. 2-3).

O fato, porém, é que as iniciativas dos movimentos africanos mencionados precisam estar mais articuladas e suas metodologias mais democratizadas. É aí onde a UPMS joga um papel aglutinador preponderante, devido à sua novidade:

\footnotetext{
${ }^{8}$ A África Austral é a parte sul de África, banhada pelo Oceano Índico na sua costa oriental e pelo Atlântico na costa ocidental e é formada pelos seguintes países: África do Sul, Angola, Lesoto, Madagáscar, Malaui, Maurícias, Moçambique, Namíbia, Suazilândia, Zâmbia, Zimbábue.
} 
[...] no seu carácter intertemático, na promoção de reflexões/articulações entre movimentos feministas, operários, indígenas, ecológicos, etc. Trata-se de criar no mundo do activismo progressista uma consciência internacionalista de tipo novo: intertemática, intercultural, radicalmente democrática (SANTOS, 2006, p. 169).

A UPMS surge, então, de um ativismo para uma globalização contra hegemônica, no âmbito do Fórum Social Mundial (FMS), “[...] centrado na ideia de que a fase actual do capitalismo global, conhecida como globalização neoliberal, exige novas formas de resistência e novas concepções de emancipação social" (SANTOS, 2006, p. 169).

Com a proposta da UPMS pretende-se superar o hiato entre teoria e prática": "Em última análise, o seu objectivo é ultrapassar a distinção entre teoria e prática, conjugando-as através de encontros sistemáticos entre os que se dedicam essencialmente à prática da transformação social e os que se dedicam essencialmente à produção teórica" (SANTOS, 2006, p. 170).

Uma das novidades da UPMS é a promoção da ecologia de saberes, implementada, segundo Santos (2008), “[...] na promoção de diálogos entre o saber científico e humanístico que a universidade produz e os saberes leigos, populares, tradicionais, urbanos, camponeses, provincianos, de culturas não ocidentais" (p. 53). Quando foi pensada, a proposta da composição da UPMS incluía três atividades principais: (1) atividades pedagógicas, (2) de pesquisa-ação para a transformação social e (3) de difusão de competências e instrumentos de tradução intertemática, transnacional e intercultural. As atividades pedagógicas, que se traduzem através de oficinas de aprendizagem coletiva, desenvolvem-se num processo que envolve o trabalho de tradução ao permitir o "[...] interconhecimento e a auto-educação com o duplo objectivo de aumentar o conhecimento recíproco entre os movimentos e organizações e tornar possíveis coligações entre eles e acções colectivas conjuntas" (SANTOS, 2006, p. 167).

\section{LIÇÕES DA UPMS EM MOÇAMBIQUE E ZIMBÁBUE}

As oficinas da UPMS em Moçambique e no Zimbábue tiveram em comum a questão da terra, alimentação, território e recursos. Tanto em Moçambique (Mumemo e Tete) como no Zimbábue (Harare), as oficinas tiveram um caráter intertemático, internacionalista e juntou movimentos de diversas lutas (camponeses, feministas, ambientalistas, direitos humanos, médicos tradicionais ${ }^{10}$, pessoas afetadas por HIV/SIDA) investigadores e acadêmicos.

O principal objetivo das oficinas foi:

[...] através do reforço de ligações e interações entre os movimentos e organizações da sociedade civil e os intelectuais, ampliar o nosso conhecimento sobre a realidade do país, contribuindo para o fortalecimento

\footnotetext{
${ }^{9}$ Santos (2006) identificou a existência de um hiato entre a teoria e a prática, o que tem consequências negativas tanto para os movimentos sociais como para as universidades e centros de pesquisa. Ou seja, se por um lado a produção teórica das universidades está dissociada das práticas sociais, por outro, os movimentos sociais "[...] sentem a falta de propostas teóricas que lhes permitam reflectir analiticamente sobre a sua prática e esclarecer os seus métodos e objectivos" (SANTOS, 2006, p. 169-170).

${ }^{10}$ Também chamados curandeiros, os médicos tradicionais assumem um papel importante na prestação de cuidados de saúde e na regulação da incerteza e dos problemas sociais dos seus utentes. Segundo Honwana (2002), os médicos tradicionais, chamados tinyanga (sing. nyanga) no sul do país, de acordo com as teorias locais, devem os seus poderes curativos, divinatórios e de eficácia ritual ao fato de serem possuídos por espíritos de defuntos, que com eles formam uma simbiose profissional e ontológica.
} 
da nossa formação e do nosso envolvimento no desenvolver de agendas e ações políticas comuns (VUNJANHE, 2013).

\title{
OFICINA DA UPMS EM MUMEMO (MAPUTO, MoÇAMiQUE): “A TERRA E A SUA APROPRIAÇÃO/PRIVATIZAÇÃO
}

A oficina de Mumemo, em Maputo, realizada entre os dias 25 e 27 de julho de 2013, debateu a complexa questão da terra e as dinâmicas que levam à sua usurpação, mas também as estratégias de luta pela sua defesa. Depois de dois dias e meio de aprendizagem, a oficina permitiu aos participantes (cerca de 35 pessoas - entre líderes de movimentos sociais e organizações da sociedade civil, ativistas e acadêmicos) um exercício de análise profunda sobre a questão. Os vários saberes compartilhados entre os e as participantes permitiram não somente uma compreensão sobre a conjuntura que define as transformações no meio rural como lhes muniram de ferramentas que possibilitaram a convicção de que a transformação é necessária.

Exemplo disso foi o surgimento de uma campanha intersetorial contra a privatização da terra em Moçambique, que juntou movimentos camponeses, feministas, ambientalistas:

\begin{abstract}
Mais de 30 organizações da sociedade civil decidiram juntar esforços para defender a terra e os recursos naturais. As organizações, que incluem movimentos de camponeses, vão lançar ainda este ano uma campanha nacional contra privatização da terra. Em cima da mesa está o projecto ProSavana $^{12}[\ldots]$. Esta decisão surge como resultado de discussões e reflexões profundas no âmbito da oficina da Universidade Popular dos Movimentos Sociais (REDAÇÃO, 2013).
\end{abstract}

De acordo com o comunicado de imprensa emitido pelos organizadores da oficina de Mumemo, a campanha iria traduzir-se em "[...] diversas atividades, entre as quais, marchas, educação popular sobre o direito à terra, caravanas de educação civil das populações rurais e urbanas sobre governação, cartas de denúncia, e técnicas de resistência à invasão dos seus territórios" (REDAÇÃ̃, 2013).

O tema da terra em Moçambique constituía até então preocupação "exclusiva" ao movimento camponês e seus aliados mais próximos. Na exceção de algumas instituições de investigação, que têm como seu objeto de pesquisa o meio rural, a vasta maioria de organizações da sociedade civil moçambicana não se identificava intimamente com a causa. No decurso da oficina, uma líder do movimento feminista declarou, inspirada e mobilizada pelo processo que para ela, a partir daquele momento a questão da terra em Moçambique passava a ser prioridade para as mulheres que ela representava ${ }^{13}$.

Foi igualmente interessante ver como a participante do movimento dos médicos tradicionais chegava a conclusões novas sobre como a ameaça da perda da terra afetaria o seu setor, mesmo que ela não fosse, necessariamente, uma produtora agrícola.

A seção final da oficina de Mumemo foi cancelada para atender a um pedido de solidariedade feito por um líder camponês de Marracuene (Sul de Maputo), no qual denunciava uma eminente demolição da sede da União Distrital de Camponeses devido

11 Tema de discussão na oficina da UPMS em Mumemo, Moçambique. Fonte: http://www.universidadepopular.org/site/pages/pt/oficinas/oficina-de-mumemo---2013.php

12 O ProSavana é um programa de parceria público-privada entre Brasil, Japão e Moçambique, para desenvolvimento agrícola no corredor de Nacala, Norte de Moçambique (UNAC, 2012).

${ }^{13}$ Esta fala foi de Graça Samo, então Diretora do Fórum Mulher e atualmente coordenadora internacional da Marcha Mundial das Mulheres. 
à construção de uma via pública de grande envergadura por uma construtora chinesa. A seção final da oficina transformou-se numa ação direta de solidariedade no local da construção e a intervenção de uma participante da Liga dos Direitos Humanos permitiu que a sede da União Distrital dos Camponeses não fosse demolida.

Em resumo, as conclusões ${ }^{14}$ a que chegaram os participantes da oficina de Mumemo foram: (1) é preciso ter conhecimento das lutas dos outros, divergências e focar para agenda única. Temos de conhecer as lutas dos outros países e fortalecer as alianças. É preciso revitalização da luta, continuamente; (2) precisamos estabelecer parcerias para realizar as nossas ações; (3) precisamos realçar as nossas bandeiras, mas devemos procurar identificar uma bandeira coletiva; (4) é importante cruzar o saber popular e saberes acadêmicos; (5) precisamos tomar em atenção a discriminação das mulheres dentro da nossa luta; (6) temos de ser práticos nas nossas ações e definir questões concretas; (7) são necessárias ações que despertem os nossos dirigentes; (8) é importante questionar ou denunciar os modelos de desenvolvimento e destruir o sistema capitalista; (9) temos que defender a nossa terra e mobilizar o povo para exercer controle sobre a terra.

\section{OFICINA DA UPMS EM TETE (MOÇAMBIQUE): “A SITUAÇÃO POLÍtICO-MILITAR E A SUA POSSÍVEL RELAÇÃO COM O BOOM DOS RECURSOS NATURAIS EM MOÇAMBQUE"}

A realização e o impacto da oficina da UPMS de Mumemo inspiraram os participantes do centro de Moçambique a proporem uma oficina na cidade de Tete, centro de Moçambique, um lugar onde, naquela altura, a extração mineira de carvão mineral constituía a maior preocupação dos movimentos sociais e das populações camponesas.

A oficina de Tete foi realizada de 28 a 30 de novembro de 2014 e contou com a presença de 25 participantes - entre eles, líderes de movimentos sociais, ativistas, líderes comunitários e acadêmicos - das províncias de Tete, Manica e Sofala (Centro do país), Niassa (Norte) e Maputo, assim como participantes de Portugal e Zimbábue.

A oficina debateu a questão da mineração em Moçambique, particularmente na província de Tete, onde se desenvolve a maior parte da exploração de carvão em Moçambique. Nesta reflexão várias questões foram levantadas tendo se concluído que os recursos minerais prejudicam mais do que beneficiam as comunidades rurais das áreas onde são extraídos.

Os participantes desta oficina realizaram uma ação de solidariedade com as famílias assentadas na vila de Cateme, um campo de assentamento que alberga 716 famílias removidas de Moatize, para dar lugar à extração de carvão pela mineração Vale.

Em resumo, as deliberações ${ }^{16}$ da oficina de Tete foram: (1) intensificar o diálogo político para a promoção da coesão e definição de uma agenda comum, dentro da sociedade civil; (2) questionar a quem interessa que esta situação (conflitos de terra e remoção de populações) permaneça; (3) fazer mais oficinas da UPMS noutros pontos do país (por exemplo, Niassa, pois o ProSavana vai se expandir para esta província); (4) fazer uma UPMS nacional; (5) participar na campanha dos 16 dias de ativismo de violência contra as mulheres; (6) fortalecer a articulação entre as organizações

\footnotetext{
${ }^{14}$ Sistematização da UPMS de Mumemo, 2013.

15 Tema de discussão na oficina da UPMS em Tete, Moçambique. Fonte: http://www.universidadepopular.org/site/pages/pt/oficinas/oficina-de-tete---2013.php

${ }^{16}$ Sistematização da UPMS de Tete, 2014.
} 
feministas; (7) partilhar experiências com países que já fizeram exploração mineira; (8) fazer pressão política da comunidade aos ministérios.

Meses depois da realização da oficina de Mumemo - e inspirado por ela - em junho de 2014 foi lançada em Moçambique uma campanha nacional de rejeição ao ProSavana $^{17}$, para impedir situações de neocolonialismo expressas através do avanço do ProSavana e das multinacionais sobre os territórios camponeses (UNAC et a., 2014). A campanha foi lançada

[...] como parte de um processo mais amplo de endurecimento da nossa luta numa mobilização conjunta das organizações da sociedade civil e movimentos de camponeses em defesa dos recursos naturais e contra a agressão, usurpação, mercantilização e possível privatização da terra (UNAC et al., 2014).

A campanha "Não ao ProSavana", ainda em curso, é possivelmente a maior mobilização e resistência popular contra um projeto de usurpação de terras na história de Moçambique pós-colonial (MONJANE, 2015). A escolha do local da realização da UPMS de Tete é peculiar por ter sido um local de forte conflito. A UPMS não só serviu para debater o tema por detrás do conflito, como a sua realização e a sua ação final serviram como ação de advocacia e solidariedade diretas. OFICINA DA UPMS EM HARARE: “TERRA, SEMENTES, ALIMENTAĈ̃̃o, ÁGUA, AS
PESSOAS E O CLIMA: 15 ANOS APÓS A REFORMA AGRÁRIA NO ZIMBÁBUE"İ

Em forma de avaliação da reforma agrária que se deu no Zimbábue em 2000, a oficina de Harare, realizada entre 12 e 14 de julho de 2016, pretendeu desenvolver uma análise profunda sobre o significado da reforma 15 anos mais tarde, assim como avaliar o estado da terra, da alimentação, das sementes e do clima nos países vizinhos, uma vez que o Zimbábue se encontra intimamente ligado a outros países da África Austral.

As principais questões de debate nesta oficina foram: (1) o que se pode aprender da reforma agrária do Zimbábue?; (2) como se entender as políticas regionais sobre a terra, sementes, alimentação e água?; (3) como é que as mudanças climáticas estão a afetar o campesinato?; (4) que ações podem ser promovidas em resposta aos desafios que o Zimbábue e a região da África Austral enfrentam no setor da alimentação, terra, água e clima?

Discutindo essas questões, a oficina pretendeu fortalecer as ligações e interações entre movimentos sociais e organizações da sociedade civil, ativistas e intelectuais da região. O objetivo era aprofundar o conhecimento sobre a realidade do Zimbábue e da região da África Austral, e assim pensar agendas e ações coletivas, a partir do entendimento de que ninguém individualmente terá a resposta às várias questões que se apresentam, mas coletivamente é possível aportar contribuições importantes e assim atuar sobre a realidade.

No final da oficina os participantes transformaram as conclusões do encontro numa declaração política ${ }^{19}$ na qual se exigiu ações no ramo das políticas agrárias,

17 Os camponeses da União Nacional de Camponeses temem que o ProSavana venha a provocar o surgimento de Comunidades Sem Terra em Moçambique; frequentes convulsões sociais ao longo do Corredor de Nacala; empobrecimento das comunidades rurais e redução de alternativas de sobrevivência; aumento da corrupção e de conflitos de interesse; poluição dos recursos hídricos e empobrecimento dos solos; desequilíbrio ecológico (UNAC, 2012).

18 Tema de discussão na oficina da UPMS em Harare, Zimbábue. Fonte: http://www.universidadepopular.org/site/media/UPMS_Harare/cartaz-UPMS-A4-web.jpg 
mineração, produção de conhecimento científico (para fortalecer as comunidades), financiamento participativo, mercados locais e ação das corporações.

Em resumo, e no que diz respeito à terra e políticas agrárias, as demandas foram: (1) políticas agrárias que suportem e promovam a agroecologia para a soberania alimentar e, para tal, acesso e uso da terra deve estar orientado para as práticas agroecológicas para a soberania alimentar; (2) defesa, democratização e aprofundamento da reforma agrária no Zimbábue; (3) imediato fim das usurpações de terras camponesas e da privatização da terra em Moçambique; (4) uma redistribuição radical de terras e implementação de uma reforma agrária na África do Sul.

Os participantes da oficina de Harare eram provenientes do Zimbábue, Moçambique, África do Sul, Costa do Marfim, Portugal e Espanha.

\section{CONCLUSÃo}

O objetivo deste ensaio foi trazer algumas lições da Universidade Popular dos Movimentos Sociais através das suas oficinas, realizadas em Moçambique e no Zimbábue. Constitui tarefa complexa mensurar os resultados de um processo de partilha de conhecimentos em curto prazo e será, naturalmente, incompleta toda a análise que se faça sobre os resultados das oficinas da UPMS em questão. Seguem, mesmo assim, algumas conclusões.

A educação popular, na sua abordagem alternativa, não é apenas uma questão de adquirir conhecimento. Constitui um espaço de análise e leitura profunda da realidade com o intuito de armar ações válidas para a mudança da realidade. É um espaço para construir alternativas, demandar transformações e criar as bases para o "povo tomar o poder". Nesse sentido, a UPMS promove a autoaprendizagem, ou mais acertadamente, a aprendizagem mútua entre pares (ativistas, lideranças de movimentos etc.) e pessoas que se dedicam à investigação e ensino para uma compreensão do mundo e do meio e a partir disso desenhar estratégias de ações em exercício da ecologia de saberes (SANTOS, 2007). A emergência da campanha "Não ao ProSavana" em Moçambique é o exemplo disso. As bases para a sua criação estavam evidentemente lá, mas foi a contribuição da oficina da UPMS que possibilitou o empreender dos primeiros passos da sua formação.

Outro aspecto relevante a referir tem a ver com o fato das oficinas da UPMS não só transformarem os participantes advindos dos movimentos e organizações de base como possibilitarem, também, a transformação dos intelectuais e profissionais das academias. Ou seja, a oportunidade de estar, três dias, num mesmo espaço de aprendizagem de forma horizontal, permitiu a todos os participantes compreenderem que se pode aprender no ato de ensinar e ensinar no ato de aprender (FREIRE, 1997). Essa compreensão, em si, é profundamente transformadora.

A oficina de Harare, no Zimbábue, ao juntar camponeses e camponesas de Moçambique (onde a terra é propriedade do Estado e grande parte do campesinato tem acesso), do Zimbábue (onde foi necessária mobilização popular e uma reforma agrária radical para arrancá-la das mãos de farmeiros, latifundiários - na sua maioria brancos) e da África do Sul (onde, a sua maioria, são trabalhadores agrícolas em explorações de farmeiros brancos), permitiu a criação de um sentimento forte de esperança por parte dos camponeses/participantes sul africanos ao aprenderem e vivenciarem a experiência da "liberdade" dos seus pares dos países vizinhos.

${ }^{19}$ A declaração pode ser consultada em: http://alice.ces.uc.pt/news/?p=5757 
As propostas alternativas de educação popular, como a UPMS, não negam necessariamente a existência da educação escolar, mas desafiam-na a reinventar-se e a aceitar a emergência de outras iniciativas populares e flexíveis que quebrem a lógica convencional da educação que não questiona as desigualdades, as hierarquias e que reduz os resultados do processo de educação à produção de capital humano capaz de (re)produzir e prestar serviços.

\section{REFERÊNCIAS}

AGYEPONG, R. Gender and African education: a critical analysis of the literature. 2001. Thesis (Masters of Education Sociology and Equity Studies in Education) - University of Toronto, Ontario, 2001.

ARENDT, H. Between Past and Future. In: ARENDT, H. What is authority? Between Past and Future. New York: The Viking Press, 1961. p. 91-141.

BONET, A. J. A. La universidad y la globalización alternativa: justicia cognitiva, diversidad epidémica y democracia de saberes. Nómadas: Revista Crítica de Ciencias Sociales y Jurídicas, v. 22, n. 2, p. 5-28, 2009.

CADORE, J. O. F. B.; THEODORO, M. P.; OLIVEIRA, V. K. Sistema internacional: Crise ou desequilíbrio? Relações Internacionais Para Educadores, v. 4, p. 7-18, 2017.

CANÁRIO, R. Prefácio. In: CAVACO, C. Aprender fora da escola: percursos de formação experiencial. Lisboa: EDUCA, 2002. p. 9.

FLEET, J. V. Africa's education crisis: in school but not learning. Brookings, UP Front, 17 sept. 2012. Disponível em: < https://www.brookings.edu/blog/up-front/2012/09/17/africas-education-crisis-inschool-but-not-learning/ >. Acesso em: 12 jul. 2018.

FREIRE, P. Educação e atualidade brasileira. São Paulo: Cortez Editora, 2001.

FREIRE, P. Pedagogia da esperança: um reencontro com a Pedagogia do oprimido. 4. ed. São Paulo: Paz e Terra, 1997.

FREIRE, P. Pedagogia da autonomia: saberes necessários à prática educativa. 25. ed. São Paulo: Paz e Terra, 2002.

FREIRE, P. Pedagogia do oprimido. 17. ed. Rio de Janeiro: Paz e Terra, 1987.

FREIRE, P. Educação como prática da liberdade. Rio de Janeiro: Paz e Terra, 1967.

GADOTTI, M. Paulo Freire na África: encontro da pedagogia freiriana com a práxis política de Amílcar Cabral. In: ROMÃO, J. E.; GADOTTI, M. Paulo Freire e Amílcar Cabral: a descolonização das mentes. São Paulo: Editora e Livraria Instituto Paulo Freire, 2012. p. 55-107.

GADOTTI, M. Universidade Popular dos Movimentos Sociais: breve história de um sonho possível. UPMS, p. 1-22, jan. 2009.

KHWAJA, M. Jack in the box: the failure of education in Sub-Saharan Africa. Fair Observer, $360^{\circ}$ Analysis, 25 sept. 2014. Disponível em: < https://www.fairobserver.com/region/africa/jack-in-the-boxthe-failure-of-education-in-sub-saharan-africa-17409/ >. Acesso em: 12 jul. 2018.

HONWANA, A. Espíritos vivos, tradições modernas: possessão de espíritos e reintegração social pósguerra no sul de Moçambique. Maputo: Promédia, 2002.

LENIN, V. I. Obras completas: tomo XXIX. Madrid: Akal Editor, 1978. Disponível em: < https://www.marxists.org/espanol/lenin/obras/oc/akal/lenin-oc-tomo-29.pdf >. Acesso em: 12 jul. 2018. 
MACHEL, S. M. Fazer da escola uma base para o povo tomar o poder. Lisboa: Nova Aurora, 1974.

MACIEL, K. DE F. O pensamento de Paulo Freire na trajetória da educação popular. Educação em Perspectiva, v. 2, n. 2, p. 326-344, jul./dez. 2011.

MONJANE, B. ProSavana em Moçambique: modelo errôneo? Brasil de Fato, 29 jul. 2015. Disponível em: < https://www.brasildefato.com.br/node/32524/ >. Acesso em: 12 jul. 2018.

NKOSI, M. Is South Africa's education system really 'in crisis. BBC News, Johannesburg, 29 jan. 2016. Disponível em: < https://www.bbc.com/news/world-africa-35427853 >. Acesso em: 12 jul. 2018.

REDAÇÃO. Sociedade civil anuncia mobilização contra privatização da terra. O País Online, 30 jul. 2013.

SANTOS, B. S. A universidade no século XXI: para uma reforma democrática e emancipatória da universidade. In: ALMEIDA FILHO, N.; SANTOS B. S. Universidade no século XXI: para uma universidade nova. Coimbra: Almedina, 2008. p. 15-78.

SANTOS, B. DE S. Para além do pensamento abissal: das linhas globais a uma ecologia dos saberes. Novos estudos, São Paulo, n. 79, p. 71-94, nov. 2007.

SANTOS, B. S. A Universidade Popular dos Movimentos Sociais. In: SANTOS, B. S. A gramática do tempo: para uma nova cultura política. São Paulo: Cortez, 2006. p. 167-178

SANTOS, B. S. Entrevista realizada no dia 26 de julho de 2011, em Coimbra. Transcrição Júlia F. Benzaquem. UPMS, p. 1-15, 26 jul. 2011. Disponível em: < http://www.universidadepopular.org/site/media/leituras_upms/BSS_entrevista_J_Bensaquen_26Julho201 1.pdf >. Acesso em: 12 jul. 2018.

UNAC. Pronunciamento da UNAC sobre o programa ProSavana. UNAC, Moçambique, 11 out. 2012. Disponível em: < http://www.unac.org.mz/index.php/documentos-de-posicao/38-pronunciamento-daunac-sobre-o-programa-prosavana >. Acesso em: 12 jul. 2018.

UNAC; LDH; JA; ADECRU; FÓRUM MULHER; ACTIONAID MOZ; AAAJC; LIVANINGO. Campanha nacional não ao ProSavana. Brasil de Fato, 02 jun. 2014. Disponível em: < https://www.brasildefato.com.br/node/28730/ >. Acesso em: 12 jul. 2018.

VUNJANHE, J. Debate-se em Tete a situação político-militar e sua relação com o boom dos recursos naturais. Alice News, Mozambique, 29 nov. 2013. Disponível em: < http://alice.ces.uc.pt/news/?p=2877 >. Acesso em: 12 jul. 2018.

Recebido em: 12 jul. 2018.

Aprovado em: 20 jul. 2018. 